\title{
A sensitivity analysis of a water quality model for a constructed wetland
}

\author{
$\underline{\text { M. E. Roberts }}^{\text {a b (D), J. Lu }}{ }^{(D)}$ b, E. Kavehei ${ }^{(D)}{ }^{b}$ and M. F. Adame ${ }^{(D)}$ b c

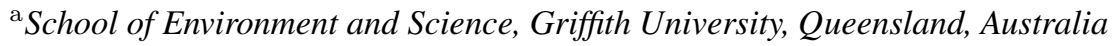 \\ ${ }^{\mathrm{b}}$ Australian Rivers Institute, Griffith University, Queensland, Australia \\ ${ }^{\mathrm{c}}$ Coastal and Marine Research Centre, Griffith University, Queensland, Australia \\ Email: m.roberts2@griffith.edu.au
}

\begin{abstract}
Excess nitrogen in storm runoff in agricultural regions contributes to poor water quality in coastal and marine environments, including the Great Barrier Reef. Constructed wetlands are one mechanism by which land holders and governments in tropical north Queensland are combating poor water quality. Wetlands are known to be effective at promoting nitrogen amelioration - reducing the nitrogen concentration of outflows relative to their inflows. Mathematical models of $n$ itrogen p rocesses in w etlands a re $\mathrm{u}$ seful for exploring the conditions under which wetlands are most effective in order to guide wetland design and management. Understanding the relative importance of, and model sensitivity to, the various biogeochemical processes (within the wetland) and the boundary conditions (influxes to the wetland) is critical to target monitoring and further research where it will best reduce uncertainty and improve decision making.

This paper presents a sensitivity analysis of a single-box compartment model for nitrogen within a wetland in tropical north Queensland. Five coupled ordinary differential equations describe the masses of nitrate $\left(\mathrm{NO}_{3}-\mathrm{N}\right)$, ammonium $\left(\mathrm{NH}_{4}-\mathrm{N}\right)$, dissolved organic nitrogen (DON), particulate organic nitrogen $(\mathrm{PON})$, and suspended sediment (SS) within the wetland and includes terms for the release and transformation of the nitrogen forms within the wetland. The sensitivity analysis includes an exploration of 21 model parameters, namely the transfer rate constants and half saturation constants, the temperature rate factor, and the nitrogen concentrations in rain, through both a vary one-at-a-time (OAT) analysis and an all-at-the-same-time analysis. The sensitivity of the model to the boundary conditions, that is the mass influxes of the various nitrogen forms and sediment entering the wetland, was explored using a OAT analysis applying a fixed proportional variation to the mass influx time series for each of $\mathrm{NO}_{3}-\mathrm{N}, \mathrm{NH}_{4}-\mathrm{N}, \mathrm{DON}, \mathrm{PON}$, and $\mathrm{S}$. The sensitivity was measured using the metrics of cumulative removal of each of total nitrogen (TN), the different nitrogen forms $\left(\mathrm{NO}_{3}-\mathrm{N}, \mathrm{NH}_{4}-\mathrm{N}, \mathrm{DON}, \mathrm{PON}\right)$, and $\mathrm{SS}$ over a four month study period for a case study wetland.
\end{abstract}

The all-at-the-same-time analyses demonstrated that while the degree of removal showed considerable variation across the parameter space, the majority (90\%) of scenarios had net TN removal, with all scenarios showing net $\mathrm{NO}_{3}-\mathrm{N}$ and net PON removal. DON was generated within the wetland under all scenarios, and ammonium was generated in $93 \%$ of cases. Understanding the conditions under which net TN generation could occur will be essential for effective management of treatment wetlands.

TN removal was PON driven, and hence very sensitive to those parameters that drive PON removal, namely particle size and density. While the absence of re-suspension processes will lead to an over-estimation of PON removal, high PON influxes indicate that settling ponds to reduce $\mathrm{PON}$ inflow may be a us eful strategy to improve wetland performance. Considering the internal processes, after settling TN was most sensitive to the ammonium release rate resulting from the mineralisation process. Ammonium was more sensitive to sediment release rates and plant uptake processes over the nitrification p rocesses, m ost likely d ue to the anaerobic conditions that prevailed within the wetland. Sensitivity (within the top 10) to the temperature rate factor was also observed for all nitrogen forms (and SS); further investigation of temperature impacts is therefore warranted, particularly in wetlands threatened by climate change.

The TN removal performance, although dominated by PON, is the combination of the different removal forms. All nitrogen forms showed sensitivity to their influx values, however the degree of sensitivity varied markedly. Ammonium was most sensitive to influx masses, with a 20\% variation in influx resulting in as much as $1000 \%$ change in the removal. In contrast, DON variation was within $100 \%, \mathrm{NO}_{3}-\mathrm{N}$ within $20 \%$, and PON within $5 \%$.

Keywords: Nitrogen, denitrification, treatment systems, Great Barrier Reef, mineralisation 


\section{INTRODUCTION}

The application of high volumes of nitrogen-rich fertilisers in agricultural regions has been identified as a significant contributor to poor water quality in marine and coastal environments (Waterhouse et al. 2017). Restored and constructed wetlands have been found to be effective at promoting nitrogen amelioration for adjacent aquatic ecosystems (Adame et al. 2019c, Kavehei et al. 2021). Water quality models have been used to understand the potential impacts of constructed wetlands on water quality. Models such as these will increasingly be used to inform the use and management of constructed wetlands to support downstream water quality targets. However, as highlighted in Kavehei et al. (2021), these models are reliant on the availability of sufficient hydrological and biogeochemical process knowledge. Understanding the relative importance of the different processes and boundary conditions (influxes) to the predicted performance of a wetland will be important to focus monitoring and research where they will have the greatest impact on reducing uncertainty.

This paper presents a sensitivity analysis of a single-box compartment model for water quality, which has been applied in the Great Barrier Reef catchments (Adame et al. 2019c, Kavehei et al. 2021). The model and a description of the sensitivity analysis methods are described in Section 2, results and a discussion in Section 3, and a short conclusion in Section 4.

\section{METHODS}

Coastal wetlands, including treatment wetlands, promote the removal of nitrogen through at least three processes: plant uptake, soil accretion, and denitrification (Adame et al. 2019c). In our wetland model,nitrogen is introduced to the wetland through in-flowing runoff and rainfall, released from decaying plant material within the wetland, and released from sediment (both bottom sediments and sediment introduced in runoff). Within the wetland, nitrogen is transformed (and ultimately removed) through the processes of mineralisation, nitrification, denitrification, and annamox. These processes rely on beneficial bacteria and are functions of the water temperature, soil carbon, $\mathrm{pH}$, redox, and the nitrogen concentrations. Nitrogen is also removed through plant uptake, and in particulate form, settling processes. Suspended sediment is removed from the water column due to settling.

These nitrogen sources, sinks and transformations can be modelled through a system of five coupled ordinary differential equations for the mass $[\mathrm{kg}]$ of nitrate $\mathrm{NO}_{3}-\mathrm{N}\left(\mathrm{NO}_{3}\right.$ in the model equations), ammonium $\mathrm{NH}_{4}-\mathrm{N}$ $\left(\mathrm{NH}_{4}\right.$ in the model equations), dissolved organic nitrogen (DON), particulate organic nitrogen (PON), and fine suspended sediment (SS)in the water column, namely:

$$
\begin{aligned}
& \frac{d \mathrm{NO}_{3}}{d t}=Q_{\text {in }} C_{\mathrm{NO}_{3}}^{\text {flow in }}-Q_{\text {out }} \frac{\mathrm{NO}_{3}}{V}+A R C_{\mathrm{NO}_{3}}^{\text {rain }}+\mathrm{NH}_{4} g\left(k_{1}, \mathrm{NH}_{4}, K_{1}\right)-a_{1} \theta^{T-20} A(1-f(N)) \\
& -A g\left(a_{2}, \mathrm{NO}_{3}, K_{a 2}\right)-\frac{a_{3}}{2} \theta^{T-20} \frac{\min \left(\mathrm{NO}_{3}, \mathrm{NH}_{4}\right) / V}{K_{a 3}+\min \left(\mathrm{NO}_{3}, \mathrm{NH}_{4}\right) / V} \\
& \frac{d \mathrm{NH}_{4}}{d t}=Q_{\text {in }} C_{\mathrm{NH}_{4}}^{\text {flow }}-Q_{\text {out }} \frac{\mathrm{NH}_{4}}{V}+A R C_{\mathrm{NH}_{4}}^{\text {rain }}-\mathrm{NH}_{4} g\left(k_{1}, \mathrm{NH}_{4}, K_{1}\right)-a_{1} \theta^{T-20} A f(N) \\
& +\operatorname{DON} g\left(k_{2}, \mathrm{DON}, K_{2}\right)+a_{4} \theta^{T-20} A+\operatorname{SS} g\left(k_{3}, \mathrm{SS}, K_{3}\right) \\
& -\frac{a_{3}}{2} \theta^{T-20} \frac{\min \left(\mathrm{NO}_{3}, \mathrm{NH}_{4}\right) / V}{K_{a 3}+\min \left(\mathrm{NO}_{3}, \mathrm{NH}_{4}\right) / V} \\
& \frac{d \mathrm{DON}}{d t}=Q_{\text {in }} C_{\mathrm{DON}}^{\text {flow }}-Q_{\text {out }} \frac{\mathrm{DON}}{V}-\operatorname{DON} g\left(k_{2}, \mathrm{DON}, K_{2}\right)+a_{5} \theta^{T-20} A+\operatorname{PON} g\left(k_{4}, \mathrm{PON}, K_{4}\right) \\
& \frac{d \mathrm{PON}}{d t}=Q_{\text {in }} C_{\mathrm{PON}}^{\text {flow in }}-Q_{\text {out }} \frac{\mathrm{PON}}{V}+a_{6} \theta^{T-20} A-\mathrm{PON} g\left(k_{4}, \mathrm{PON}, K_{4}\right)-\mathrm{PON} \frac{-w_{s} \mathrm{PON}}{z_{\mathrm{av}}} \\
& \frac{d \mathrm{SS}}{d t}=Q_{\text {in }} C_{\mathrm{SS}}^{\text {flow in }}-Q_{\text {out }} \frac{\mathrm{SS}}{V}-\mathrm{SS} \frac{w_{\mathrm{SS}} t}{z_{a v}} .
\end{aligned}
$$

The notation $g(\xi, N, K)=\xi \theta^{T-20} \frac{N / V}{N / V+K}$ is used for simplicity, and the ammonium preference equation is $f(N)=\frac{\mathrm{NH}_{4} \mathrm{NO}_{3}}{\left(\mathrm{NH}_{4}+V K_{N}\right)\left(\mathrm{NO}_{3}+V K_{N}\right)}+\frac{\mathrm{NH}_{4} V K_{N}}{\left(\mathrm{NH}_{4}+\mathrm{NO}_{3} / V\right)\left(\mathrm{NO}_{3}+V K_{N}\right)}$. Refer to Table 1 for a summary of all parameters, units and their expected values from the literature.

The sensitivity of the nitrogen transformation model was explored using two approaches: a one-at-a-time (OAT) variation in the model parameters and influx masses, and an all-at-the-same-time variation in the model 


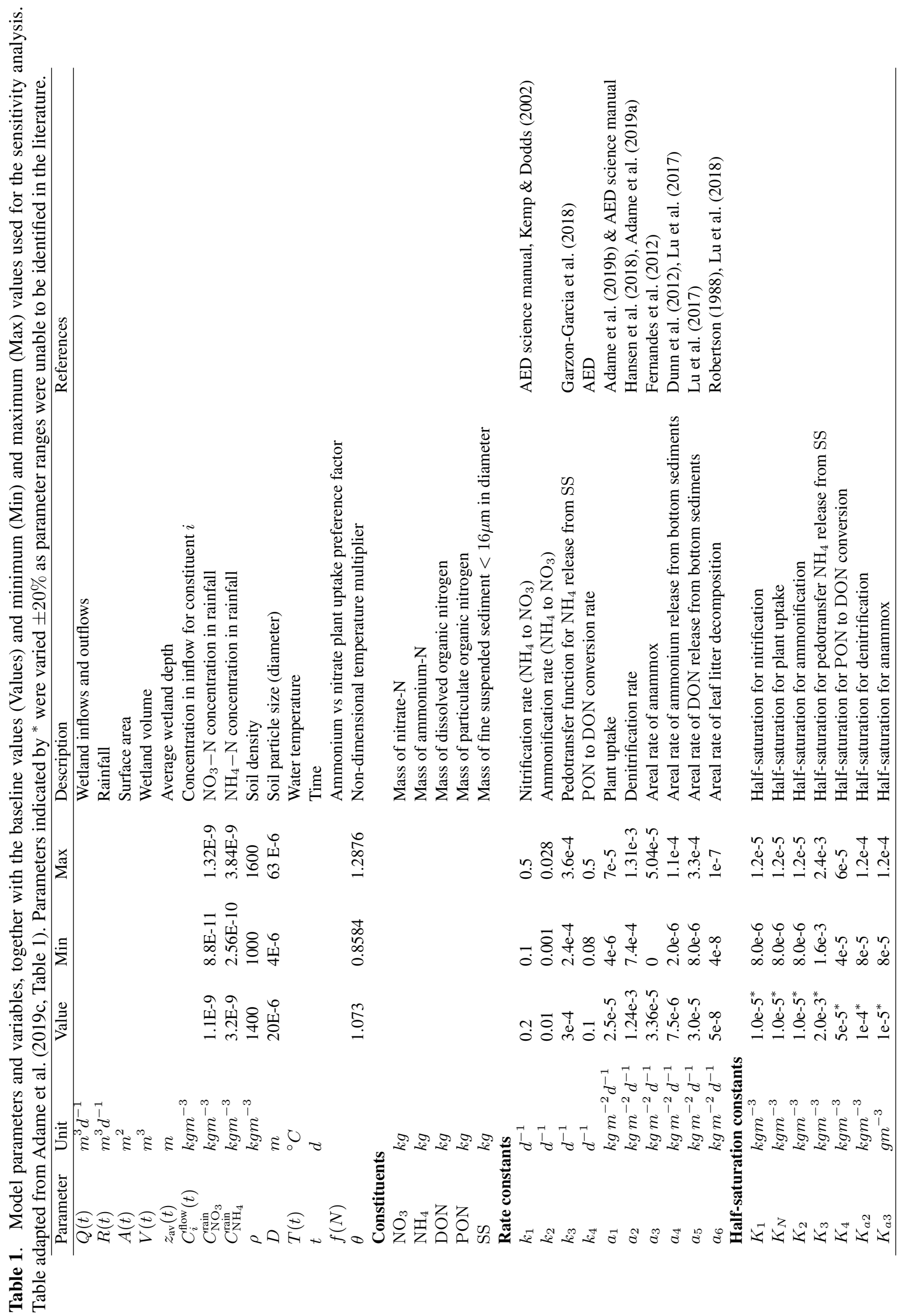


parameters, with parameters selected using a Latin Hypercube Sampling strategy. Sensitivity was measured by the variation in the modelled cumulative mass removal of TN, the different nitrogen forms and SS in wetland TW03, a constructed wetland in tropical North Queensland. The wetland model was run over a four-month period (1 February 2020 to 1 June 2020). Measured water-table heights were used to form volume, surface area and flux time-series based on theoretical relationships. Modelled sediment and nitrogen mass influxes were formed based on a limited number of observations. 18 observations for $\mathrm{NH}_{4}-\mathrm{N}, \mathrm{NO}_{3}-\mathrm{N}$, and SS were used to form models of concentration influx using linear regression, while the median values for PON (1 observation) and DON (18 observations) were used (see Kavehei et al. (2021) for details). The mean (standard deviation) influx masses [kg/d] during the study period were $\mathrm{NO}_{3}-\mathrm{N}$ : $1.14(7.57), \mathrm{NH}_{4}-\mathrm{N}: 0.35$ (0.72), DON: 1.63 (4.19), PON: 12.47 (20.18), and SS: 390.58 (2288.57), with runoff flux [m³/d]: 8580.49 (22061.77).

\subsection{One-at-a-time sensitivity analysis}

An OAT parameter sensitivity analysis was conducted to explore the model sensitivity to the rate and halfsaturation constants, rain nitrogen concentrations, and mass influxes. This approach considers both the sensitivity to the boundary conditions (mass-influx) and the wetland internal biological nitrogen processing conditions (model parameters). Sensitivity was measured using the cumulative removal of TN, the different nitrogen forms and SS across the study period. The baseline values are those resulting from the model parameters and influx values from the Kavehei et al. (2021) study. The feasible range for each of the 21 model parameters were identified from the literature (Table 1). Where literature values were not available, a $20 \%$ error margin was considered. As the aerial rate of DON, $a_{5}$, and ammonium, $a_{4}$, release from bottom sediments are connected processes, a fixed relationship of $a_{5}=4 a_{4}$ was used. A classical tornado plot, which compares the deviation from the baseline values arising from the lower and upper parameter values indicated a non-linear response to many of the parameters. Therefore 10 equally spaced values between the upper and lower bounds were used; the maximum and minimum cumulative removal were retained for each of the six constituents independently.

The mass influxes were increased (or decreased) by a fixed proportion across all days. Variations of $\pm 2.5, \pm 5$, \pm 10 , and $\pm 20 \%$ were considered for the different nitrogen forms and SS individually (i.e. 40 scenarios). The plot is arranged to illustrate the parameters and influx scenarios the model is most sensitive to. Sensitivity is measured by the maximum variation in the cumulative removal; the top 10 parameters and influx scenarios are shown.

\subsection{All-at-the-same-time sensitivity analysis}

Latin hypercube sampling was used to generate a parameter space for 100 repeat runs for the 21 model parameters. The samples were generated using the lhsmdu (version 1.1) (Moza 2020) package in Python3. A uniform distribution was assumed for all parameters, with minimum and maximum values as shown in Table 1. A time-series of cumulative removal for the nitrogen forms and SS was calculated for each run. The mean and standard deviation was calculated for each day. Results are shown in Figure 3. The proportion of runs resulting in net removal and net generation of each constituent over the study period was calculated.

\section{RESULTS AND DISCUSSION}

\subsection{Boundary condition impacts on nitrogen removal}

We investigated both boundary and wetland internal biological nitrogen processing conditions on nitrogen removal from wetlands. Our results showed that the TN removal from wetlands is very sensitive to PON boundary conditions (see Figures 1 and 2). TN outfluxes were dominated by PON (as were the influxes), 69\% of TN cumulative removal in the baseline case was due to PON. Consequently TN removal is most sensitive to the parameters that control settling, namely soil particle size $D$ and density $\rho$. This may be partially due to the exclusion of re-suspension and erosion processes within the model, which would be expected to increase the concentrations of both SS and PON within the outflow. However, even in the absence of re-suspension processes, the wetlands are expected to act as settling basins and thus high PON removal is expected. This removal is however temporary, as mineralisation processes release this nitrogen back into the water column. In order to increase the performance of wetlands on nutrient removal, reducing sediments and particulate nutrients that are associated with sediments in the wetland inflow via settling ponds are usually recommended (Lawrence \& Breen 1998). For individual nitrogen species, ammonium is particularly sensitive to influx masses, where a margin error of as little as $20 \%$ on a single nitrogen form could result in the over or under-estimation of ammonium removal by $1000 \%$ (see Figure 2). However, under these same conditions, TN removal was 
Roberts et al., A sensitivity analysis of a water quality model for a constructed wetland
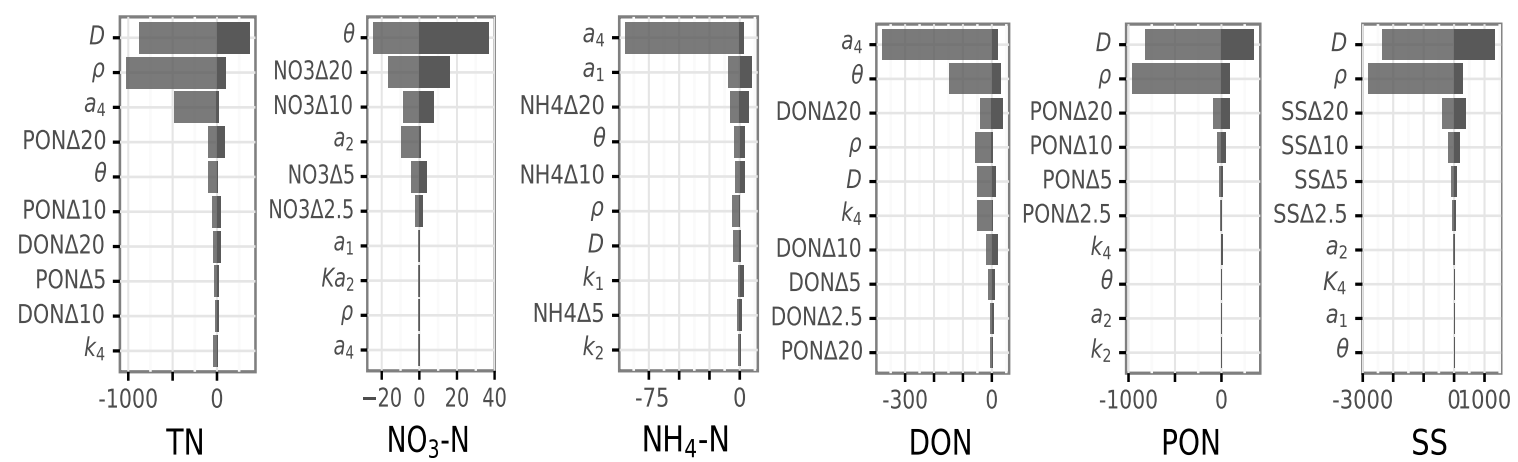

Figure 1. Tornado plot illustrating the model sensitivity of the cumulative removal of the nitrogen forms and SS to model parameters and influx conditions using a one-at-a-time analysis. Variation in the cumulative removal of each constituent is shown for the 15 most sensitive parameters, that is the parameters exhibiting the greatest net variation in the extremes of the variation observed. Variation in the boundary condition is indicated using the notation $N \Delta A$, where $N$ is the constituent, and $\Delta A$ is the mass influx percentage change.

observed to vary by only $5 \%$. All nitrogen forms were observed to be sensitive to the influx mass variation, but on markedly different scales. E.g. $20 \%$ influx variation of single nitrogen form (either DON, PON, or nitrate) can result in $100 \%$ variation of removal for DON, but only $5 \%$ for $\mathrm{PON}$, and $20 \%$ for $\mathrm{NO}_{3}-\mathrm{N}$, respectively. This result illustrates that the model is unequally sensitive to different scenarios depending on the nitrogen form of concern. The impacts of boundary conditions can be particularly critical during high flow events that carry and deliver high proportions of particulate nutrients into wetlands. Therefore, there is a high need to measure accurate influx data for each nitrogen form.

\subsection{Wetland internal biological nitrogen processing impacts on nitrogen removal}

Considerable variation in net removal was observed across the parameter range explored (see Figure 3). Within the parameter ranges we explored in this study, $10 \%$ of scenarios result in TN release rather than removal. This TN removal performance is the combination of removal performance from the different nitrogen forms. In which, all scenarios showed net nitrate and PON removal. In contrast, $7 \%$ of scenarios showed ammonium removal and all scenarios showed net DON release. This result indicates wetlands are more likely to serve as nitrate and PON sink for wetland inflows but ammonium and DON sources for wetland outflows. This can indicate the occurrence of the mineralisation process in wetlands in which microbes decompose organic matter and produce ammonium and DON (Kavehei et al. 2021).

The most sensitive biological nitrogen processing parameter for TN removal is the release rate of ammonium from bottom sediment $\left(a_{4}\right)$ via the mineralisation process (see Figure 1). This indicates a good understanding of sediment ammonium release might be critical to estimate the overall performance of wetlands on TN removal. Sediment ammonium release rate can be variable in wetlands with different redox conditions (McLatchey \& Reddy 1998) and organic matter conditions with different quantities and qualities (mineralisation capability) in the sediment (Chapman et al. 2019).

Without considering boundary conditions, the nitrate removal is mostly driven by the denitrification process $\left(a_{2}\right)$ as showed in the OAT sensitivity analysis (see Figure 1), which is also consistent with results from other studies. Also, as expected, PON removal is driven by the settling processes $(D$ and $\rho$ ) as re-suspension and erosion within the wetlands was not included in our model. The changes of ammonium are more sensitive to the sediment ammonium release $\left(a_{4}\right)$ and plant uptake $\left(a_{1}\right)$ processes, compared to the nitrification process $\left(k_{1}\right)$ within the parameter ranges we explored. This is likely due to the anaerobic conditions that occur in the wetland, which restrict the conversion of ammonium into nitrate via the nitrification pathway. Similarly, the changes of DON are driven by the sediment DON release rate $\left(a_{5}=4 a_{4}\right)$ and the PON to DON conversion rate $\left(k_{4}\right)$ from the mineralisation process, compared to the ammonification rate $\left(k_{2}\right)$. This further indicates the need to explore the impact of organic matter mineralisation on the $\mathrm{TN}$ removal performance.

The model is also exhibiting some sensitivity to $\theta$, the temperature factor for nitrogen conversion, for most nitrogen forms. This indicates water temperature is important in regulating the nitrogen processing rate. In addition to the thermodynamics of the chemical reactions, microbial mediated nitrogen processes also rely on enzyme activities that are temperature dependent. This result indicates that climate change might trigger 
Roberts et al., A sensitivity analysis of a water quality model for a constructed wetland
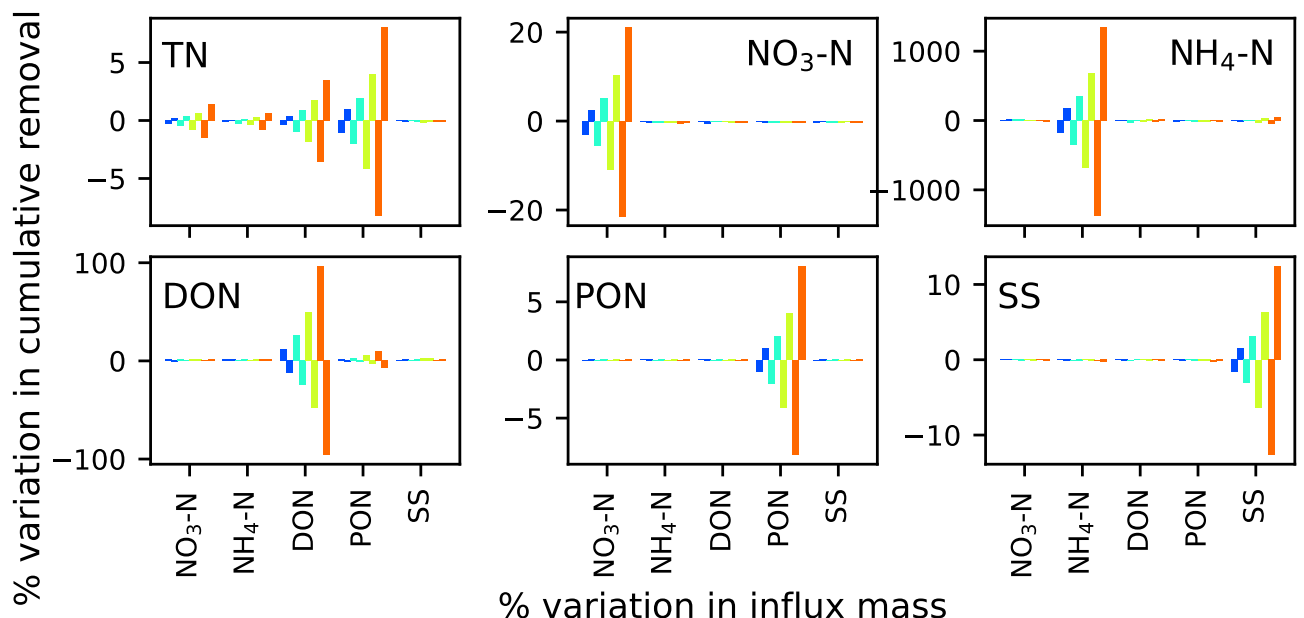

$\%$ variation in influx mass

$\pm 2.5 \% \quad \pm 5 \%$

$\pm 10 \%$

$\pm 20 \%$

positive $\mathbb{X}$ negative

Figure 2. Sensitivity of the model to variation in the mass influx of the nitrogen forms and SS measured through the proportional variation in the cumulative removal $[\mathrm{kg}]$ of the constituents over the study period. The $\mathrm{x}$-axis indicates the variation in the mass influx of the various constituents using a one-at-a-time approach, with the y-axis showing the system response. The colour of each bar indicates the proportional variation of the mass influx, with hatching indicating a decrease in the mass influx, and no hatching indicating an increase.
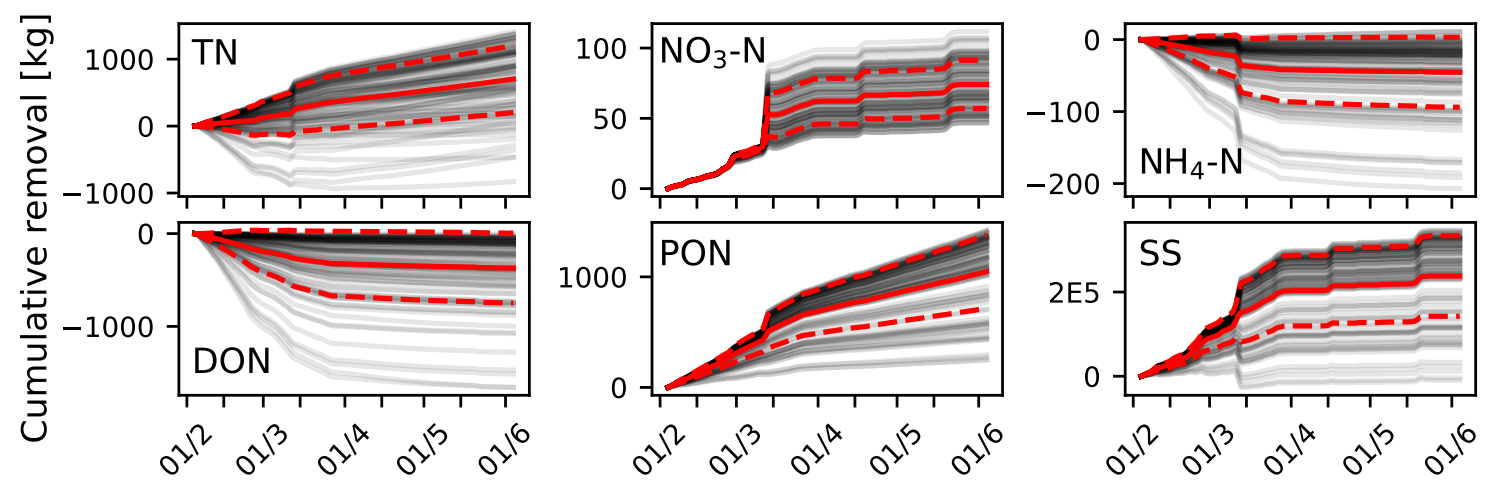

Figure 3. Cumulative removal $[\mathrm{kg}]$ of $\mathrm{TN}$, the different nitrogen forms, and SS over the study period for 100 runs with parameters selected using a LHS strategy. The mean (line) \pm standard deviation (dashed) are indicated for each day by the red lines.

the change of wetland nitrogen removal performance depending on which nitrogen process pathway is more sensitive to the temperature change. Further investigation of temperature impacts, therefore, is needed for wetlands that are potentially threatened by climate change.

Half-saturation concentrations are of less importance overall for all nitrogen pathways. This might be because we only varied them by $\pm 20 \%$ in our sensitivity analysis due to a lack of literature support for wider range variations. Future studies on the variation of the half-saturation concentrations might further support a more comprehensive sensitivity analysis.

\section{CONCLUSION}

This sensitivity analysis illustrates the importance of both boundary and biological regulated nitrogen processing conditions on the predicted performance of constructed wetlands in tropical environments. Boundary conditions, especially PON influx when PON is the dominant nitrogen form in the inflow, are consistently important for the TN removal performance for wetlands. In terms of internal wetland dynamics, wetlands might shift from a TN sink to a TN source when high mineralisation activity from the bottom sediment overtake other 
nitrogen removal processes, e.g., denitrification and plant uptake processes. Our sensitivity analysis indicates that is is critical to monitor the wetland nutrient influx and measure critical nitrogen processing pathways to better evaluate the performance of wetlands on nitrogen removal.

\section{ACKNOWLEDGEMENT}

This project has received funding from the Queensland Government through the Queensland Water Modelling Network. MFA is funded through an Advance Queensland Industry Engagement Fellowship. We thank the farmers that allowed us to work on their property and for sharing their knowledge.

\section{REFERENCES}

Adame, M. F., Franklin, H., Waltham, N. J., Rodriguez, S., Kavehei, E., Turschwell, M. P., Balcombe, S. R., Kaniewska, P., Burford, M. A. \& Ronan, M. (2019a), 'Nitrogen removal by tropical floodplain wetlands through denitrification', Marine and Freshwater Research 70(11), 1513. doi: 10.1071/mf18490.

Adame, M. F., Reef, R., Wong, V. N. L., Balcombe, S. R., Turschwell, M. P., Kavehei, E., Rodríguez, D. C., Kelleway, J. J., Masque, P. \& Ronan, M. (2019b), 'Carbon and nitrogen sequestration of melaleuca floodplain wetlands in tropical australia', Ecosystems 23(2), 454-466. doi: 10.1007/s 10021-019-00414-5.

Adame, M. F., Roberts, M. E., Hamilton, D. P., Ndehedehe, C. E., Reis, V., Lu, J., Griffiths, M., Curwen, G. \& Ronan, M. (2019c), 'Tropical Coastal Wetlands Ameliorate Nitrogen Export During Floods', Frontiers in Marine Science 6, 769-18. doi: 10.3389/fmars.2019.00671.

Chapman, S. K., Hayes, M. A., Kelly, B. \& Langley, J. A. (2019), 'Exploring the oxygen sensitivity of wetland soil carbon mineralization', Biology Letters 15(1), 20180407. doi: 10.1098/rsbl.2018.0407.

Dunn, R. J., Welsh, D. T., Jordan, M. A., Waltham, N. J., Lemckert, C. J. \& Teasdale, P. R. (2012), 'Benthic metabolism and nitrogen dynamics in a sub-tropical coastal lagoon: Microphytobenthos stimulate nitrification and nitrate reduction through photosynthetic oxygen evolution', Estuarine, Coastal and Shelf Science 113, 272-282. doi: https://doi.org/10.1016/j.ecss.2012.08.016.

Fernandes, S. O., Bonin, P. C., Michotey, V. D., Garcia, N. \& LokaBharathi, P. A. (2012), 'Nitrogen-limited mangrove ecosystems conserve $\mathrm{n}$ through dissimilatory nitrate reduction to ammonium', Scientific Reports 2(1). doi: 10.1038/srep00419.

Garzon-Garcia, A., Burton, J., Franklin, H. M., Moody, P. W., Hayr, R. W. D. \& Burford, M. A. (2018), 'Indicators of phytoplankton response to particulate nutrient bioavailability in fresh and marine waters of the great barrier reef', Science of The Total Environment 636, 1416-1427. doi: 10.1016/j.scitotenv.2018.04.334.

Hansen, A. T., Dolph, C. L., Foufoula-Georgiou, E. \& Finlay, J. C. (2018), 'Contribution of wetlands to nitrate removal at the watershed scale', Nature Geoscience 11(2), 127-132. doi: 10.1038/s41561-017-0056-6.

Kavehei, E., Roberts, M., Cadier, C., Griffiths, M., Argent, S., Hamilton, D., Lu, J., Bayley, M. \& Adame, M. (2021), 'Nitrogen processing by treatment wetlands in a tropical catchment dominated by agricultural landuse', Marine Pollution Bulletin 172, 112800. doi: 10.1016/j.marpolbul.2021.112800.

Kemp, M. J. \& Dodds, W. K. (2002), 'The influence of ammonium, nitrate, and dissolved oxygen concentrations on uptake, nitrification, and denitrification rates associated with prairie stream substrata', Limnology and Oceanography 47(5), 1380-1393. doi: 10.4319/lo.2002.47.5.1380.

Lawrence, I. \& Breen, P. F. (1998), Design guidelines: Stormwater pollution control ponds and wetlands., Cooperative Research Centre for Freshwater Ecology.

Lu, J., Bunn, S. E. \& Burford, M. A. (2018), 'Nutrient release and uptake by littoral macrophytes during water level fluctuations', Science of The Total Environment 622-623, 29-40. doi: 10.1016/j.scitotenv.2017.11.199.

Lu, J., Faggotter, S. J., Bunn, S. E. \& Burford, M. A. (2017), 'Macrophyte beds in a subtropical reservoir shifted from a nutrient sink to a source after drying then rewetting', Freshwater Biology 62(5), 854-867. doi: 10.1111/fwb.12904.

McLatchey, G. P. \& Reddy, K. R. (1998), 'Regulation of organic matter decomposition and nutrient release in a wetland soil', Journal of Environmental Quality 27(5), 1268-1274. doi: 10.2134/jeq1998.00472425002700050036x.

Moza, S. (2020), 'sahilm89/lhsmdu: Latin hypercube sampling with multi-dimensional uniformity (lhsmdu): Speed boost minor compatibility fixes'. doi: 10.5281/ZENODO.3929531.

Robertson, A. (1988), 'Decomposition of mangrove leaf litter in tropical australia', Journal of Experimental Marine Biology and Ecology 116(3), 235-247. doi: 10.1016/0022-0981(88)90029-9.

Waterhouse, J., Schaffelke, B., Bartley, R., Eberhard, R., Brodie, J., Star, M., Thorburn, P., Rolfe, J., Ronan, M., Taylor, B. \& Kroon, F. (2017), '2017 Scientific Consensus Statement'. 